\title{
Suppressive and additive effects in protection mediated by combinations of monoclonal antibodies specific for merozoite surface protein 1 of Plasmodium yoelii
}

\author{
Irosoki Eslava', Gilberto Payares², Beatriz M Pernia ${ }^{3}$, Anthony A Holder ${ }^{4}$, Lilian M Spencer ${ }^{3 *}$
}

\begin{abstract}
Background: The merozoite surface protein (MSP)-1 is a target antigen of protective immunity and a malaria vaccine candidate. The nature of this protective immune response warrants further investigation: although specific antibody is thought to play a major role, the mechanisms of protection are still unclear. Monoclonal antibodies (mAbs) specific for the C-terminus of MSP-1 from Plasmodium yoelii have been shown previously to provide protection against challenge infection when administered by passive immunization to mice. Three protective mAbs were re-examined and, in particular, the effect of combinations of antibodies on the protection provided was studied. It was found that a combination of two antibodies can either provide additive protective effects or result in a suppression of protection. In this report the importance of antibody subclass and epitope specificity in the outcome of these passive immunization experiments are discussed.

Methods: The minimum protective dose (MPD) for each mAb was determined, and then combinations of antibody at their MPD were investigated for their ability to control parasitaemia and promote survival in groups of mice. Mice were inoculated over three days with the MPD and challenged with a blood stage infection of the virulent $P$. yoelii $17 \mathrm{XL}$. The resultant parasitaemia was assessed daily on Giemsa-stained blood films. Following the infection the presence of MSP-1 specific antibodies in the sera was monitored, and the proliferative responses of cells in the spleen of protected mice were measured.

Results: Combining antibodies resulted in either an additive effect on protection, with reduced peak parasitaemia and better survival, or resulted in a suppression of protection over that achieved by a single antibody alone. An additive effect was observed when B6 and F5 that have the same isotype and similar fine specificity, were combined. However, a combination of $\mathrm{mAb} D 3$, an IgG2a, with either B6 or F5 (both IgG3) suppressed protection, an effect that may have been due to the combination of different isotypes or to the different fine specificity of the antibodies.

Conclusions: These results suggest that a combination of protective antibodies with either the same or different isotypes can produce either an additive or a suppressive effect in passive immunization. This phenomenon may be important in better understanding immunity in this experimental mouse model of malaria.
\end{abstract}

\footnotetext{
* Correspondence: Ispencer@usb.ve

${ }^{3}$ Department of Cell Biology, Simón Bolívar University, AP 89000, Caracas, Venezuela
} 


\section{Background}

Malaria control remains one of the most important priorities for improving public health in tropical and subtropical areas of the world. The World Health Organization estimates that half the world's population is at risk and there are about 250 million clinical cases in Africa, Asia and South-America, with up to a million deaths a year due to malaria [1]. The malaria parasite has evolved complex strategies to adapt to its host and evade the immune system.

Recent studies on immunity to malaria have been largely carried in the field using human material or in the laboratory using appropriate murine models. A large number of parasite proteins have been studied as antigens, including the merozoite surface protein (MSP)-1 [2]. The merozoite is a specialized cell that invades red blood cells, representing an essential extracellular stage of the asexual blood cycle. Proteins on the merozoite surface are, therefore, accessible to humoral immunity and there is considerable interest in understanding how antibodies binding to these proteins can either prevent erythrocyte invasion or target merozoites for phagocytosis and clearance. MSP-1 is a high-molecular-weight protein synthesized as a precursor during schizogony, which is found on the surface of the merozoite as a complex of fragments derived by proteolytic processing of the precursor $[2,3]$. There is abundant evidence to suggest that the C-terminal region of this molecule, represented by a $42 \mathrm{kDa}$ fragment on the merozoite surface $\left(\mathrm{MSP}_{42}\right)$, is the target of antibodies that are important in protective immunity [4]. At invasion this fragment is further cleaved into two further fragments, one of which is the C-terminal $19 \mathrm{kDa}$ fragment $\left(\mathrm{MSP}-1_{19}\right)$ that is comprised of two epidermal growth factor-like domains and remains on the surface of the parasite through erythrocyte invasion.

In the present work, three monoclonal antibodies (mAbs) that bind to the C-terminus of Plasmodium yoelii MSP-1 were used, which all individually provide protection against a challenge infection following passive immunization of mice [5]. The three antibodies that have both different and similar fine specificities and isotypes, are D3 (IgG2a), F5 (IgG3) and B6 (IgG3). B6 and F5 both bind to the first epidermal growth factor (EGF) domain in MSP-1 19 with a similar fine specificity, whilst D3 binds to an epitope that is only found on the intact MSP- $1_{42}$. The aim of this study was to investigate the possible suppressive, synergistic or additive effects of combining these mAbs in passive immunization experiments using groups of $\mathrm{BALB} / \mathrm{c}$ mice.

\section{Methods}

Monoclonal antibodies (mAbs)

Hybridomas expressing the mAbs B6 (IgG3), D3 (IgG2a) and $\mathrm{F} 5$ (IgG3) were maintained and cultured as described previously [5]. Immunoglobulins were purified from hybridoma culture supernatants using protein G-Sepharose according to the manufacturer's recommendations.

\section{Passive immunization and parasite challenge}

Eight week-old female BALB/c mice bred under specificpathogen-free conditions were used in groups of six. The purified mAbs dissolved in phosphate buffered saline (PBS) were administered by intraperitoneal injection on three occasions, i.e. one day before, one day after and on the day of challenge infection. The parasite challenge was administered by intravenous injection of five thousand parasitized erythrocytes, at least one hour after administration of the mAb. The parasite used for the challenge was the lethal 17XL strain of P. yoelii; the parasite was stored at $-80^{\circ} \mathrm{C}$ and passaged once in a mouse before use in these experiments. Blood stage parasitaemia was assessed daily on smears made from tail blood and stained with Giemsa's reagent.

The amount of antibody to be used in the passive immunization experiments was determined in preliminary experiments carried out to establish the minimum protective dose (MPD), using a range down to one fifth of the $1.5 \mathrm{mg}$ amount used previously [5]. All animal experimentation was approved by the Ethical Review board of USB.

\section{Western blot assay}

To detect antibodies to MSP-1 in the sera from the immunized mice, a western blot assay was used. A recombinant protein comprised of glutathione S-transferase fused to the two C-terminal MSP-1 epidermal growth factor-like domains (GST-MSP-1 $1_{19}$ ) was expressed in Escherichia coli and purified from the bacterial lysates as described previously [6]. The purified protein was subjected to SDS-PAGE and then electrophoretically transferred to nitrocellulose paper (NCP, $0.2 \mu \mathrm{m}$ pore size; Schleicher \& Schuell), at $120 \mathrm{~mA}$ in a transblotting chamber (Bio-Rad, Instruments), for one hour at $4^{\circ} \mathrm{C}$, using $25 \mathrm{mM}$ Tris- $\mathrm{HCl}, 150 \mathrm{mM}$ glycine, $20 \% \mathrm{v} / \mathrm{v}$ methanol, by the method of Towbin and coworkers [7]. After transfer, the blots were blocked by incubation with a solution of $3 \% \mathrm{w} / \mathrm{v}$ non-fat milk in PBS for $30 \mathrm{~min}$ at room temperature, and washed three times $(3 \times)$ in PBS, containing $0.05 \% \mathrm{v} / \mathrm{v}$ Tween-20. Blots were then incubated for one hour at room temperature with a solution of primary antibody diluted 1:200 in PBS, washed $3 \times$ and incubated in a solution of affinity purified goat anti-mouse immunoglobulin conjugated to horseradish peroxidase, at a 1:1,000 dilution (Sigma), for a further one hour. The blots were washed again 3 times and antibody binding was detected by incubation in a solution of $3 \mathrm{mg} \mathrm{ml}^{-1} 4$-chloro-1-napthol in 


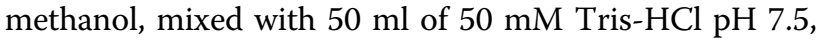
and $30 \mu \mathrm{L}$ of $30 \% \mathrm{H}_{2} \mathrm{O}_{2}$. The colour reaction was stopped by washing with $\mathrm{H}_{2} \mathrm{O}$.

\section{Cell proliferation assay}

Cells were harvested from the spleens of naïve mice or surviving mice in the group that had been passively immunized with the combination of B6 and F5 mAbs, and placed into culture in sterile 96-well tissue culture plates with minimum essential medium (MEM) supplemented with $20 \mathrm{mM}$ L-glutamine, $16.5 \mathrm{mM} \mathrm{NaHCO} 3$, $10 \% \mathrm{v} / \mathrm{v}$ foetal calf serum and $2 \%$ antibiotic (penicillin/ streptomycin) solution. A suspension of $2 \times 10^{5}$ cells was placed in each well with 10 or $20 \mu \mathrm{g}$ of either recombinant $\mathrm{MSP}-1_{19}$ protein or concanavalin A (ConA) as a lymphocyte mitogen control, or buffer alone as a negative control. After 48 hours of incubation at $37^{\circ} \mathrm{C}$ and in an atmosphere of $5 \% \mathrm{v} / \mathrm{v} \mathrm{CO}_{2}$ in air, cell viability and proliferation was assessed spectrophotometrically following the addition of $20 \mu \mathrm{l}$ of MTS reagent ([3-(4,5-dimethylthiazol-2-yl)-5-(3-carboxymethoxyphenyl)-2-(4-sulfophenyl)-2H-tetrazolium, inner salt; MTS (a) ], CellTiter $96^{\circ}$ AQueous, Promega). The reduction in absorbance at $490 \mathrm{~nm}$ for the treated and untreated control cultures was measured and compared.

\section{Statistical analysis}

Each experimental value is presented as the mean of six replicates \pm standard deviation. Once normality and homogeneity criteria were satisfied, statistical analyses were carried out by one-way ANOVA, taking $\alpha=5 \%$ $(\mathrm{p}<0.05)$ as significant.

\section{Results}

In the first series of studies, the MPD was established for each $\mathrm{mAb}$. For each of the three mAbs a total dose of $0.3 \mathrm{mg}$ (i.e. $0.1 \mathrm{mg}$ delivered on three occasions) modulated the course of infection but was not protective. At a higher dose (0.6 mg of mAb D3; $0.9 \mathrm{mg}$ of B6 and $1.2 \mathrm{mg}$ of F5) a clear protective effect was seen for each of the antibodies (data not shown). In the control group inoculated with PBS alone a fulminating infection resulted in high parasitaemia with no survival past day 10. In contrast passive immunization with $0.6 \mathrm{mg}$ of $\mathrm{mAb}$ D3 delayed the course and reduced the peak of parasitaemia as well as improving survival (Figure 1). All animals were alive on day 10 and $20 \%$ survived to the end of the experiment on day 30. There was a 2-day delay in patent parasitaemia, which then increased to $63 \%$ only by day 14 followed by clearance of parasites by day 22 . The difference in parasitaemia between experimental and control group, for example at day 9 , was statistically significant.

Then, the consequence of passive immunization with mixtures of the mAbs at their MPD was examined, expecting an additive effect. The effect of immunization with a combination of D3 and B6 mAbs is shown in Figure 2. As can be seen from this graph, passive

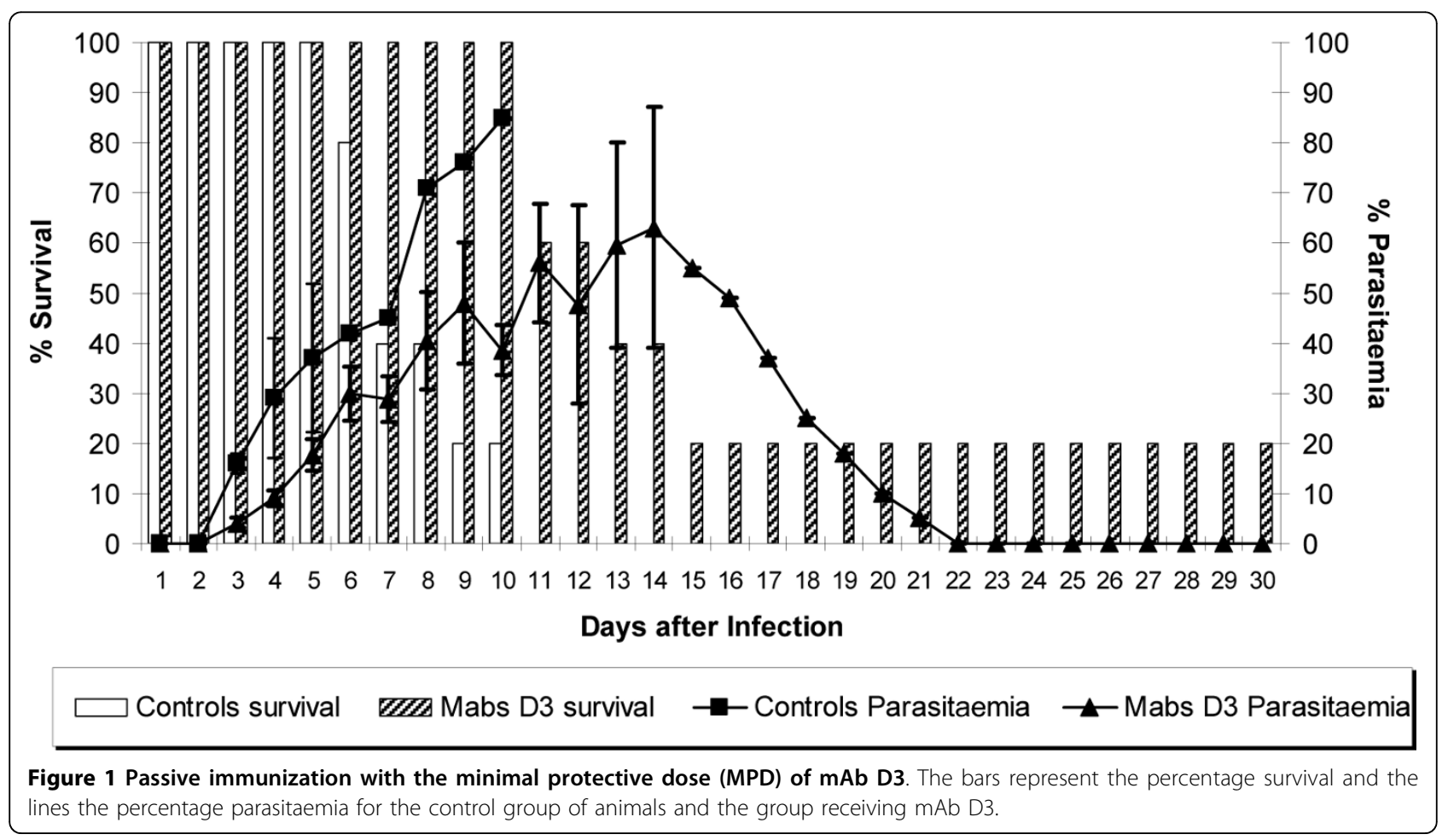




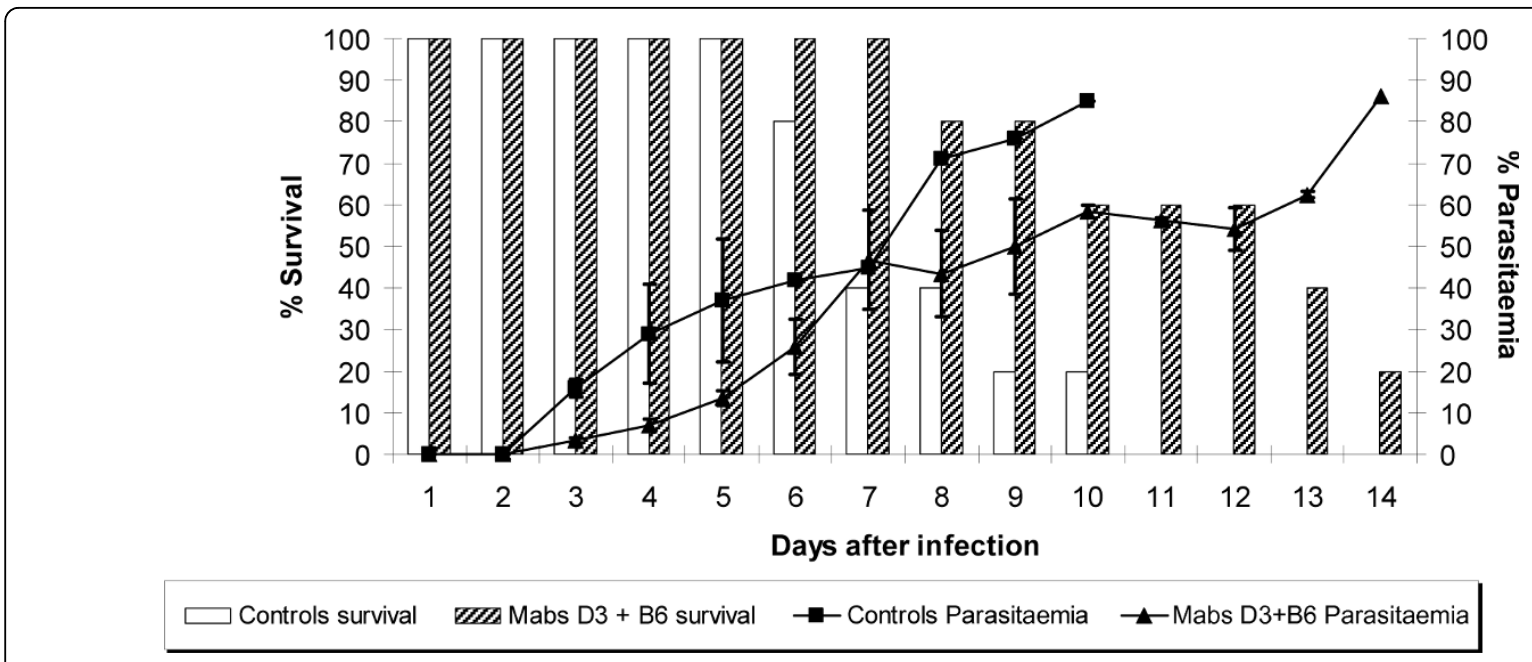

Figure 2 Passive transfer experiment with the mAbs D3 and B6 in combination. The bars represent the percentage of survival and the lines the percentage of parasitaemia.

immunization with a mixture of these antibodies produced a lower level of protection than that achieved with individual mAbs alone. There was a protective effect when the survival rate and parasitaemia were compared to that in the control group injected with PBS alone in which group there was nearly $90 \%$ parasitaemia and no survival beyond day 10 . However, parasite development in the presence of this combination resulted in both higher mortality ( $20 \%$ survival by day 14 ) and parasitaemia ( $85 \%$ on day 14 ) when compared with the protection given by B6 (57\% parasitaemia) or D3 (63\% parasitaemia) alone. Thus the suppressive effect on parasitaemia of the combination was less than that achieved by the individual antibodies given separately. A similar suppressive effect was observed in a passive immunization experiment using a combination of the D3 and F5 mAbs. As shown in Figure 3, the combination of D3 and F5 resulted in 70\% parasitaemia at day 9 compared to $63 \%$ and $66 \%$ for D3 and F5 alone, respectively. On this occasion, none of the control mice survived beyond day 5 with a $70 \%$ parasitaemia, consistent with a higher parasite challenge inoculum.

The third possible combination of antibodies was mAbs B6 with F5, both of which are of the IgG3 isotype.

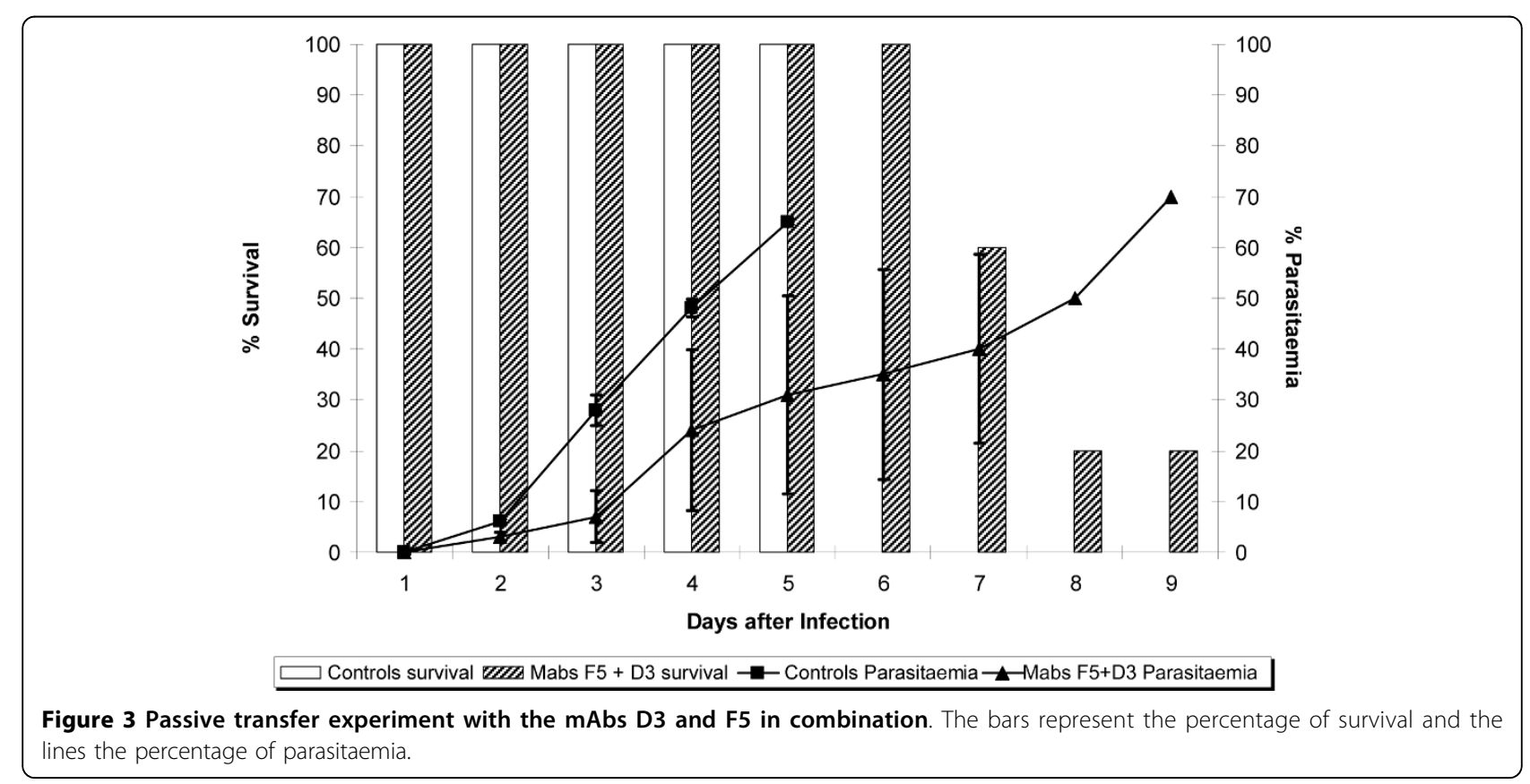




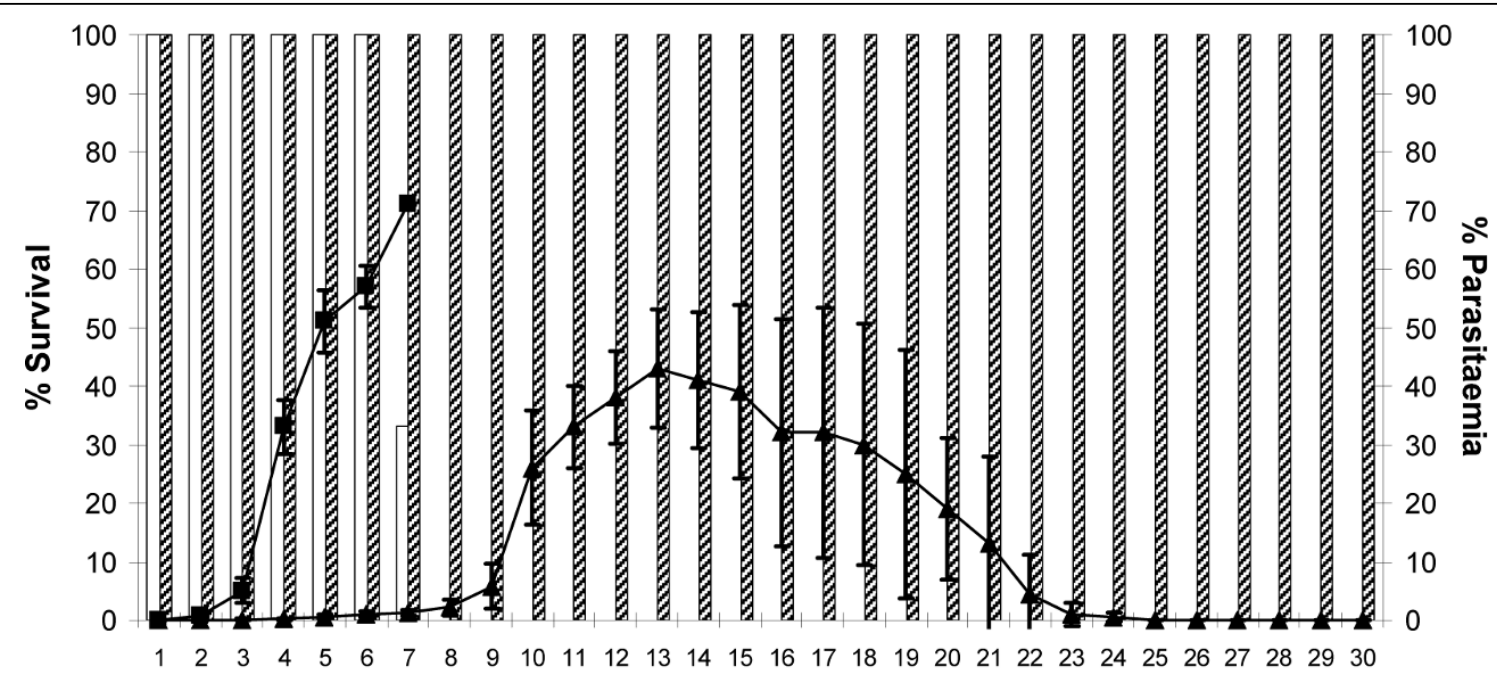

Days after Infection

$\square$ Controls survival $\mathbb{Z W}$ Mabs F5 + B6 survival $\rightarrow$-Controls Parasitaemi —-Mabs F5+B6 Parasitaemia

Figure 4 Passive transfer experiment with the mAbs B6 and F5 together in combination. The bars represent the percentage of survival and the lines the percentage of parasitaemia.

In this case the outcome of the passive immunization with the combination was a clear additive effect, as shown in Figure 4. In this experiment none of the control group survived beyond day 7 and with a parasitaemia greater than $70 \%$. In contrast all the mice that received this combination of antibodies survived to the end of the experiment at day 30 with no detectable parasites after day 23. Furthermore the maximum parasitaemia was $43 \%$, considerably lower than that in the groups given mAbs B6 and F5 separately. In these passive immunization experiments, from day 2 there was a significantly lower parasitaemia $(\mathrm{p} \leq 0.05)$ than in the control group. In order to confirm that the mice from the group protected by passive immunization with $\mathrm{B} 6$ and F5 did not have subpatent parasites after clearance of parasitaemia, a $200 \mu \mathrm{l}$ blood sample was taken and inoculated intravenously into a naive mouse; no parasites were detected in these animals during the 30 -day monitoring period.

To confirm the presence of antibodies to MSP-1 in the surviving animals from the different groups, serum samples were examined by western blotting against a GST-MSP $1_{19}$ fusion protein. Antibodies were detected in all of the serum samples from mice that had been administered the mAbs either alone or in combination except for the group that received a mixture of B6 and F5 mABs (Figure 5).

To examine whether or not passive immunization and challenge infection induced an immune response,

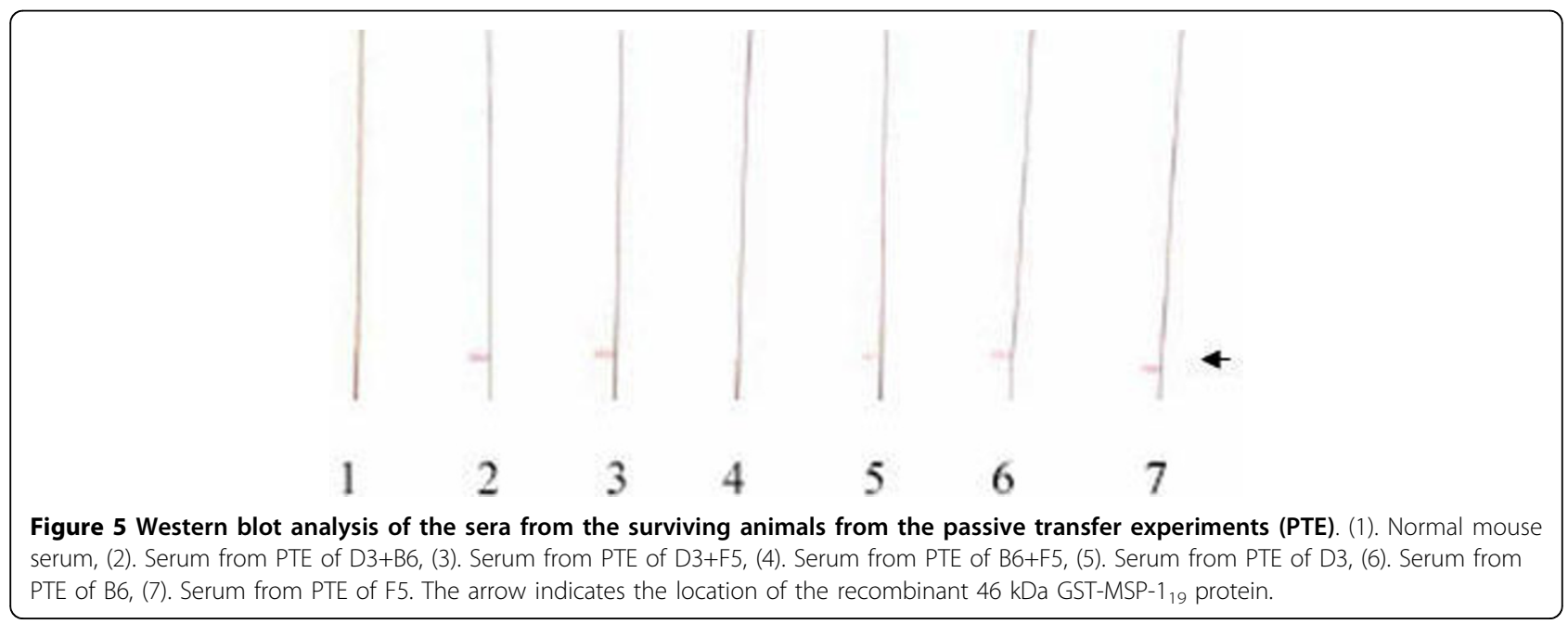


Table 1 Cell proliferation assay following recovery from infection

\begin{tabular}{cccc}
\hline Spleen cell source & Stimulant & Amount $(\boldsymbol{\mu g})$ & Absorbance \\
\hline Normal & MSP-1 $_{19}$ & 10 & 0.090 \\
Normal & MSP-1 $_{19}$ & 20 & 0.072 \\
F5+B6 recovered & Con A & 10 & 0.302 \\
F5+B6 recovered & Con A & 20 & 0.329 \\
F5+B6 recovered & MSP-1 $_{19}$ & 10 & 0.338 \\
F5+B6 recovered & MSP-1 $_{19}$ & 20 & 0.445 \\
\hline
\end{tabular}

Normal spleen corresponds to cells from naïve mice as negative control and cells stimulated with Con A are a positive control of proliferation/viability, detected in the MTS assay. A blank value of 0.147 , obtained with normal spleen cells without stimulation with MSP- $1_{19}$ or ConA, was subtracted from each absorbance value. Each absorbance value represents the mean from three independent experiments.

splenic lymphocytes from the group immunized with the combination of B6 and F5 antibodies were examined for their ability to proliferate in the presence of recombinant MSP-1, as shown in Table 1. Lymphocyte proliferation in the presence of recombinant MSP-1 protein was similar to that in the presence of the mitogen Con A, and much higher than the proliferative response to MSP-1 $1_{19}$ of lymphocytes from naïve mice, indicating that an immune response had been induced in these protected animals.

\section{Discussion}

It is well established that immunization of mice with the C-terminal region of MSP-1 is able to induce protective immunity $[6,8,9]$. What is less clear are the protective mechanisms responsible. There is good evidence that antibody plays an important role in the protection induced $[5,6,10]$, but the whether the antibody works by directly neutralizing merozoites and blocking erythrocyte invasion or primarily through Fc-mediated actions needs further investigation.

The ability of three monoclonal antibodies specific for the merozoite surface protein MSP-1 to provide protection against infection with the rodent malaria parasite $P$. yoelii by passive immunization was investigated. In particular we have examined the effect of combining pairs of antibodies on their protective capacity. These antibodies are of the G3 (B6 and F5) and G2a (D3) isotypes. Both B6 and F5 bind to an epitope within the first EGF-like domain of $P$. yoelii MSP-1 $1_{19}$, whereas D3 binds to an epitope in the longer $\mathrm{MSP}_{42}$ fragment, which is formed from the two subdomains of MSP $1_{33}$ and $\mathrm{MSP}_{19}$ [5]. The epitopes binding B6 and F5 overlap but are not identical $[5,11]$, but their proximity to the epitope of D3 is unclear since the epitope for this antibody appears to be a conformational epitope that is formed only in the intact MSP-1 $1_{42}$. In the first step of this study, the minimum protective dose (MPD) was determined for each antibody as $0.6,0.9$ and $1.2 \mathrm{mg}$ for
mAbs D3, B6 and F5, respectively. In the second step of the study, the ability of combinations of two antibodies at their MPD to provide protection by passive immunization was measured. Mixtures of D3 and B6 or D3 and F5 antibodies were less effective than the single antibodies alone, whereas a mixture of F5 and B6 was more effective than either of these two antibodies alone.

The mechanism(s) by which these three antibodies provide protection following passive immunization is unknown. There are several mechanisms that have been suggested to explain the protective effect of antibodies to merozoite surface proteins [12], and a number of possible mechanisms have been identified for antibodies directed against the C-terminal region of Plasmodium falciparum MSP-1 [4]. These mechanisms may depend on the antibody alone, such as inhibition of proteolytic processing of MSP-1 or merozoite agglutination, or depend on an Fc-mediated component such as opsonisation of merozoites and phagocytosis. In both types of mechanism it is likely that the antibody avidity and concentration are important. In the case of antibody mediated inhibition of invasion through inhibition of MSP-1 processing the fine specificity of antibody binding is crucial. Antibodies that bind to the first EGF-like domain, such as B6 and F5 can inhibit processing but the importance of this mechanism in protection against $P$. yoelii has not been established. If both $\mathrm{B} 6$ and $\mathrm{F} 5 \mathrm{mAbs}$ are providing protection through this mechanism, it is not surprising that the protection provided by passive immunization with a mixture of the two is additive since this is equivalent to increasing the concentration of the protective antibody specificity. In fact, the mice in this group fully resolved their parasitaemia since a blood sample that was transferred from each mouse into naïve recipient mice failed to cause infection. However, it is also possible that an acquired immune response as indicated by the lymphocyte proliferation (Table 1) and resulting from the parasite infection may have also contributed to this clearance.

The failure of mixtures of B6 with D3 or F5 with D3 to provide additive protection is more difficult to explain. mAb D3 does not bind to MSP1 19 alone and yet is very effective at providing protection on passive immunization; a corresponding antibody specific for $P$. falciparum MSP-1 has not been described or a mechanism evaluated. The suppressive effect of the mixture on the control of parasitaemia highlights the potential complexity of antibody interactions within a polyclonal response. It has already been established that some antibodies, which do not inhibit MSP-1 processing, can be defined as blocking antibodies in this mechanism because they block the binding of the inhibitory antibody $[4,13,14]$. It is not known whether or not the binding of D3 to MSP-1 competes with and blocks the binding of $\mathrm{B} 6$ or $\mathrm{F} 5 \mathrm{mAbs}$, or vice versa. In either case 
the consequence may be a reduction in the protective capacity of the mixture of antibodies, as seen in the results presented here.

An alternative explanation may reflect the importance of Fc-mediated mechanisms in the protection mediated by passive immunization with antibodies to MSP-1, which may depend on the isotype of the mAb. It has already been established that Fc-mediated effects are important in immunity dependent on antibodies binding to MSP-1 [15,16], although some studies have shown that this mechanism is not essential $[17,18]$. One possible explanation for the results is that the IgG3 isotype has a greater capacity to fix complement than IgG2a [19]. Although the Fc $\gamma R I$ receptor of macrophages has a high affinity for IGg2a, it binds IgG3 with fivefold higher affinity $[20,21]$. In competition studies, it has been demonstrated that IgG3 can inhibit IgG2a binding to Fc $\gamma$ RI receptor [21]. Earlier work with a different IgG3 specific for MSP-1 also showed that it was effective in passive protection [10]. This interpretation would suggest that IgG3 is the best immunoglobulin sub-class for use in passive immunization to eliminate the parasite from the blood.

Smith and Taylor-Robison [22] measured the level of different immunoglobulin isotypes induced during infections of mice with virulent and avirulent lines of Plasmodium chabaudi and Plasmodium yoelii. A non-lethal infection was characterized by early upregulation of IgG2a and late upregulation of IgG1, whereas in a lethal infection a slow and reduced IgG2a correlated with rapid fatal outcome before G1 synthesis. Unfortunately these authors did not evaluate the IgG3 isotype.

The proliferation of spleen cells following stimulation with MSP- $1_{19}$ was observed for the group of mice that was protected by passive transfer of B6 and F5 antibodies, and which was similar in magnitude to that induced by the mitogen ConA and was not replicated when the spleen cells came from normal BALB/c mice. Since the passive immunization did not result in sterile immunity it is likely that the infection induced an acquired immune response in these animals. This immune response may have contributed to the observed control of infection, in addition to that resulting from the presence of the B6 and F5 antibodies. In fact, antibodies to MSP- $1_{19}$ were not detected by western blotting in the serum samples from the mice in this group taken after the infection had been cleared, suggesting that all of the passively transferred antibodies had been consumed and other mechanisms might have provided the final clearance of parasites.

\section{Conclusions}

These studies highlight the fact that monoclonal antibodies binding to the $\mathrm{C}$-terminus of MSP-1 can provide protection by passive immunization. However, the outcome of using combinations of protective antibodies, which have both the same or different isotypes and different epitopes, can produce additive or suppressive effects in passive immunization experiments. These observations highlight the complexity of the interaction of antibodies with the surface of the merozoite and may be important in understanding immunity in this experimental mouse model of malaria. Whilst passive immunization with single antibodies may have potential clinical therapeutic application [23], combinations of antibodies would need to be evaluated very carefully. The results are important in the context of malaria vaccine design since stimulation of the appropriate antibody response either by antigen engineering or by use of appropriate adjuvant may be a critical component in vaccine development.

\section{Acknowledgements}

This investigation was financed in part by a grant from the DID-USB (Decanato de Investigación de la Universidad Simón Bolívar), and AH is funded by the MRC (U117532067). We thank Cristina Castelli for her critical review of this paper and Ana Hilda Marquez for her technical assistance.

\section{Author details}

${ }^{1}$ School of Bioanalysis, Central University of Venezuela, Caracas, Venezuela. ${ }^{2}$ Institute of Experimental Biology, Central University of Venezuela, Caracas, Venezuela. 르epartment of Cell Biology, Simón Bolívar University, AP 89000, Caracas, Venezuela. ${ }^{4}$ Division of Parasitology, MRC National Institute for Medical Research, Mill Hill, London, UK.

\section{Authors' contributions}

IE contributed to the performance of the passive immunization experiments and to drafting the manuscript. GP performed the passive transfer experiments and western blotting experiment. BP contributed to analysis of the data and drafting the manuscript. AH contributed to the final preparation of the manuscript. LS contributed to study design, data analysis, performance of the cell proliferation assays and manuscript writing. All authors read and approved the manuscript.

\section{Competing interests}

The authors declare that they have no competing interests.

Received: 7 August 2009

Accepted: 10 February 2010 Published: 10 February 2010

\section{References}

1. World Health Organization: World Malaria Report 2008.http://apps.who.int/ malaria/wmr2008/.

2. Holder AA: The precursor to major merozoite surface antigens: structure and role in immunity. Prog Allergy 1988, 41:72-97.

3. Blackman MJ, Ling IT, Nicholls SC, Holder AA: Proteolytic processing of the Plasmodium falciparum merozoite surface protein-1 produces a membrane-bound fragment containing two epidermal growth factorlike domains. Mol Biochem Parasitol 1991, 49:29-33.

4. Holder AA: The carboxy-terminus of merozoite surface protein 1: structure, specific antibodies and immunity to malaria. Parasitology 2009, 1-12.

5. Spencer Valero LM, Ogun SA, Fleck SL, Ling IT, Scott-Finnigan TJ, Blackman MJ, Holder AA: Passive immunization with antibodies against three distinct epitopes on Plasmodium yoelii merozoite surface protein 1 suppresses parasitemia. Infect Immun 1998, 66:3925-3930.

6. Ling IT, Ogun SA, Holder AA: Immunization against malaria with a recombinant protein. Parasite Immunol 1994, 16:63-67. 
7. Towbin H, Staehelin T, Gordon J: Electrophoretic transfer of proteins from polyacrylamide gels to nitrocellulose sheets: procedure and some applications. Proc Natl Acad Sci USA 1979, 76:4350-4354.

8. Daly TM, Long CA: A recombinant 15-kilodalton carboxyl-terminal fragment of Plasmodium yoelii yoelii 17XL merozoite surface protein 1 induces a protective immune response in mice. Infect Immun 1993, 61:2462-2467.

9. Hirunpetcharat C, Tian JH, Kaslow DC, van Rooijen N, Kumar S, Berzofsky JA, Miller LH, Good MF: Complete protective immunity induced in mice by immunization with the 19-kilodalton carboxyl-terminal fragment of the merozoite surface protein-1 (MSP1[19]) of Plasmodium yoelii expressed in Saccharomyces cerevisiae: correlation of protection with antigenspecific antibody titer, but not with effector CD4+ T cells. J Immunol 1997, 159:3400-3411.

10. Majarian WR, Daly TM, Weidanz WP, Long CA: Passive immunization against murine malaria with an IgG3 monoclonal antibody. J Immunol 1984, 132:3131-3137.

11. Benjamin PA, Ling IT, Clottey G, Valero LM, Ogun SA, Fleck SL, Walliker D, Morgan WD, Birdsall B, Feeney J, Holder AA: Antigenic and sequence diversity at the $\mathrm{C}$-terminus of the merozoite surface protein-1 from rodent malaria isolates, and the binding of protective monoclonal antibodies. Mol Biochem Parasitol 1999, 104:147-156.

12. Ramasamy R, Ramasamy M, Yasawardena S: Antibodies and Plasmodium falciparum merozoites. Trends Parasitol 2001, 17:194-197.

13. Blackman MJ, Scott-Finnigan TJ, Shai S, Holder AA: Antibodies inhibit the protease-mediated processing of a malaria merozoite surface protein. $J$ Exp Med 1994, 180:389-393.

14. Guevara Patino JA, Holder AA, MCBride JS, Blackman MJ: Antibodies that inhibit malaria merozoite surface protein-1 processing and erythrocyte invasion are blocked by naturally acquired human antibodies. J Exp Med 1997, 186:1689-1699.

15. Mclntosh RS, Shi J, Jennings RM, Chappel JC, de Koning-Ward TF, Smith T, Green J, van Egmond M, Leusen JH, Lazarou M, et al: The importance of human FcgammaRl in mediating protection to malaria. PLoS Pathog 2007, 3:e72.

16. Pleass RJ, Ogun SA, McGuinness DH, Winkel van de JG, Holder AA, Woof JM: Novel antimalarial antibodies highlight the importance of the antibody Fc region in mediating protection. Blood 2003, 102:4424-4430.

17. Rotman HL, Daly TM, Clynes R, Long CA: Fc receptors are not required for antibody-mediated protection against lethal malaria challenge in a mouse model. J Immunol 1998, 161:1908-1912.

18. Vukovic P, Hogarth PM, Barnes N, Kaslow DC, Good MF: Immunoglobulin G3 antibodies specific for the 19-kilodalton carboxyl-terminal fragment of Plasmodium yoelii merozoite surface protein 1 transfer protection to mice deficient in Fc-gammaRI receptors. Infect Immun 2000, 68:3019-3022.

19. Yuan R, Clynes R, Oh J, Ravetch JV, Scharff MD: Antibody-mediated modulation of Cryptococcus neoformans infection is dependent on distinct Fc receptor functions and IgG subclasses. J Exp Med 1998, 187:641-648.

20. Ravetch JV, Clynes RA: Divergent roles for Fc receptors and complement in vivo. Annu Rev Immunol 1998, 16:421-432.

21. Gavin AL, Barnes N, Dijstelbloem HM, Hogarth PM: Identification of the mouse IgG3 receptor: implications for antibody effector function at the interface between innate and adaptive immunity. J Immunol 1998, 160:20-23.

22. Smith EC, Taylor-Robinson AW: Parasite-specific immunoglobulin isotypes during lethal and non-lethal murine malaria infections. Parasitol Res 2003, 89:26-33.

23. Pleass RJ, Holder AA: Opinion: antibody-based therapies for malaria. Nat Rev Microbiol 2005, 3:893-899.

doi:10.1186/1475-2875-9-46

Cite this article as: Eslava et al: Suppressive and additive effects in protection mediated by combinations of monoclonal antibodies specific for merozoite surface

protein 1 of Plasmodium yoelii. Malaria Journal 2010 9:46.

\section{Submit your next manuscript to BioMed Central and take full advantage of:}

- Convenient online submission

- Thorough peer review

- No space constraints or color figure charges

- Immediate publication on acceptance

- Inclusion in PubMed, CAS, Scopus and Google Scholar

- Research which is freely available for redistribution

Submit your manuscript at www.biomedcentral.com/submit 